\title{
O manual escolar de Língua Portuguesa do 10 Ciclo do Ensino Básico: inquietações em torno da desigualdade de género na escola
}

The portuguese language book of the 1st Cycle of Basic Education: concerns about gender inequality in school

El libro de texto de Lengua portuguesa del 1 음 ciclo de Educación Básica: la preocupación por la desigualdad de género en la escuela

Florbela Samagaio $^{1}$

DOI: http://dx.doi.org/10.20435/serie-estudos.v23i48.1120

\begin{abstract}
Resumo: O presente artigo tem como objetivo fundamental alertar para a desigualdade de género que poderá estar presente nos manuais escolares. Essa sensibilização para o tema afigura-se-nos pertinente na medida em que, em Portugal, existe um dispositivo legislativo e normativo, relativamente sólido, que procura prevenir esse tipo de situação. Contudo, na nossa opinião, não será suficiente. Nesse sentido, o artigo propõe como paradigma pedagógico adequado à escola da sociedade moderna o paradigma do professor como profissional reflexivo, crítico e problematizador, sendo este o principal interlocutor do discurso pedagógico oficial junto das crianças. O artigo apresenta uma análise de conteúdo realizada ao Manual de Língua Portuguesa do 4응 ano de escolaridade do 1ำ Ciclo do Ensino Básico, inspirada na metodologia proposta por vários autores, entre eles Eugénio Brandão, nos anos 70 em Portugal, a partir da qual se poderá verificar o desequilíbrio na veiculação das imagens no feminino e no masculino assim como a sugestão de criação de territórios simbólicos de significados assentes nos estereótipos de género. A análise é efetuada ao nível das imagens e ao nível dos textos e conclui que existe uma significativa desigualdade de género no referido material de estudo. A questão central que se coloca é que os manuais escolares integram a vida escolar e quotidiana das crianças, podendo conduzir à cristalização de ideias preconcebidas sobre o género através do processo de socialização.
\end{abstract}

Palavras-chave: professor reflexivo; desigualdade de género; manual escolar .

${ }^{1}$ Escola Superior de Educação Paula Frassinetti, Cidade do Porto, Portugal. 


\begin{abstract}
The main objective of this article is to alert to the gender inequality that may be present in school textbooks. This awareness of the issue is relevant because, in Portugal, there is a relatively strong legislative and regulatory mechanism which seeks to prevent this type of situation. However, in our view, it The main objective of this article is to alert to the gender inequality that may be present in school textbooks. This awareness of the issue is relevant because, in Portugal, there is a relatively strong legislative and regulatory mechanism which seeks to prevent this type of situation. However, in our view, it will not be enough. In this sense, the article proposes as pedagogical paradigm appropriate to the school of modern society the paradigm of the teacher as a reflexive, critical and problematizing professional, being this the main interlocutor of the official pedagogical discourse with the children. The article presents an analysis of the contents of the Manual of Portuguese Language of the 4th year of primary school education, inspired by the methodology proposed by several authors, among them Eugénio Brandão in the 1970s in Portugal, from which one can verify the imbalance in the transmission of images in the feminine and masculine, as well as the suggestion of creation of symbolic territories of meanings based on gender stereotypes. The analysis is carried out at the level of the images and at the level of the texts and concludes that there is a significant gender inequality in said study material. The central issue is that textbooks integrate children's school and daily life and may lead to the crystallization of preconceived ideas about gender through the process of socialization.
\end{abstract}

Keywords: reflective teacher; gender inequality; school handbook.

Resumen: El presente artículo tiene como objetivo fundamental alertar sobre la desigualdad de género que podrá estar presente en los manuales escolares. Esta toma de conciencia del tema que nos parece relevante en la medida en que, en Portugal, hay un dispositivo legislativo y reglamentario, relativamente sólido, que busca prevenir este tipo de situaciones. Sin embargo, en nuestra opinión, no será suficiente. En este sentido, el artículo propone como paradigma pedagógico adecuado a la escuela de la sociedad moderna el paradigma del profesor como profesional reflexivo, crítico y problematizador, siendo éste el principal interlocutor del discurso pedagógico oficial entre los niños. El artículo presenta un análisis de contenido realizado en el Manual de la Lengua Portuguesa cuarto grado del 1er ciclo de la educación básica, inspirado en la metodología propuesta por varios autores, entre ellos Eugenio Brandão en los años 70 en Portugal, a partir del cual se puede verificar el desequilibrio en la transmisión de las imágenes en el femenino y en el masculino, así como la sugerencia de creación de territorios simbólicos de significados basados en los estereotipos de género. El análisis se efectúa al nivel de las imágenes y al nivel de los textos y concluye que existe una significativa desigualdad de género en el referido material de estudio. La cuestión central que se plantea es que los manuales escolares integran la vida escolar y cotidiana de los niños, pudiendo conducir a la cristalización de ideas preconcebidas sobre el género a través del proceso de socialización.

Palabras clave: profesor reflexivo; desigualdad de género; manual escolar. 


\section{INTRODUÇÃO}

\subsection{Da instrução à reflexão: breves notas em torno da urgência de um outro paradigma pedagógico para a sala de aula}

"A educação é a acção exercida pelas gerações adultas sobre aquelas que ainda não estão maduras para a vida social. Tem por objeto suscitar e desenvolver na criança um certo número de estados físicos, intelectuais e morais que lhe exigem a sociedade política no seu conjunto e o meio ao qual se destina particularmente."

(E. Durkheim, 2007, p. 53)

O sistema educativo passou por várias fases históricas sendo que a cada uma delas corresponderá um discurso pedagógico oficial (BERNSTEIN, 1986). A escola, espaço privilegiado da educação da criança no mundo ocidental, reflete as ideias e as maneiras de ser, de estar e de pensar das ideologias de uma época. Não obstante o tempo histórico, podemos referir que a educação possui intrinsecamente uma dimensão social, a qual se traduz nos diferentes tipos de interações, que se estabelecem no âmbito do processo de socialização, designadamente entre gerações.

E. Durkheim (1857 - 1917) considerava a dimensão social associada à ação das gerações adultas sobre as gerações mais novas, visto que estas ainda não se encontravam preparadas para a vida social. Essa ação era uma exigência da sociedade política, em geral, que visava proporcionar o desenvolvimento físico, social e cognitivo na criança. Para Durkheim (2007), a educação é uma socialização metódica. Na dimensão social da educação, intervêm diferentes atores sociais como a família, a escola, os mass-media e outras associações. A educação encontra na escola, enquanto instituição social, um contexto privilegiado de educação. Acresce que a escola constitui o espaço público por excelência da infância, é, nas palavras de M. Sarmento (2000a), o lugar do oficio de aluno da criança.

Sem pretender fazer uma análise exaustiva do sentido e significado da escola ao longo dos últimos tempos, gostaríamos de salientar que diferentes enquadramentos sociopolíticos influenciaram a sociedade, em particular a função e o discurso pedagógico oficial da escola.

No séc. XIX, a escola encontrava-se marcada pelos pressupostos do paradigma pedagógico da instrução (TRINDADE; COSME, 2010). Esse paradigma defendia 
que ensinar equivale a instruir. Procurando chegar a todos, a escola tornou-se uma instituição especializada na educação das gerações mais novas e massificou-se. Interessava fazer chegar às crianças o conhecimento e o saber considerados socialmente adequados para o aluno médio. Podemos afirmar que a escola tinha, como objetivos fundamentais, a homogeneização cultural e política da sociedade. Importa recordar que massificação não significa democratização. Na verdade, a escola parece assumir-se mais como um instrumento interessado em contribuir para a estratificação social e cultural das sociedades (BOURDIEU, 2002) e, desse modo, como um dispositivo de gestão política destas. Nessa perspetiva, a Escola, ao reger-se por um enciclopedismo curricular, cujos conhecimentos são reproduzidos sem que se cuide de saber até que ponto têm significado para aqueles que os reproduzem, leva à inibição do conhecimento como ato construtivo, à limitação da curiosidade e ao retraimento da reflexão e do espirito crítico. Uma Escola que, ao reprimir os saberes específicos dos alunos, bem como as suas experiências de vida, porque não os entende como escolarmente rentáveis (PERRENOUD,1990), deixa de oferecer a esses alunos infinitas possibilidades de se desenvolverem como coautores do conhecimento e como cidadãos participativos.

Nesse sentido, e perante uma Escola que se afirma como um lugar de instrução, importa perguntar, como faz Rui Canário (1999), se a Escola pode continuar a ser um espaço onde o único ator que faz as perguntas é o mesmo que já sabe as respostas ou se o ato de ensinar pode continuar a ser gerido em função daquelas questões cujas respostas já se encontram plenamente determinadas. Também, e de acordo com o mesmo autor, podemos perguntar se nas escolas se pode continuar a desvalorizar opiniões e respostas que, embora legítimas e adequadas, não são as respostas corretas, e se a escola não deverá ser um contexto onde se pratica e se desenvolve um conjunto de competências cognitivas, sociais e éticas, em vez de se divulgar informações sobre essas práticas (CANÁRIO, 1999). Na verdade, o paradigma da instrução desvaloriza a experiência e os saberes dos alunos. O papel fundamental do professor será o de expor os saberes de modo a que os alunos os saibam reproduzir fielmente.

Ora a sociedade moderna não se poderá contentar com uma mera reprodução académica dos saberes. Essas questões fazem sentido e terão de ser compreendidas à luz das exigências das sociedades modernas, sociedades da informação e do conhecimento. "Esta tipificação é indicativa da importância que nelas ocupa 
a cultura, qualquer que seja o entendimento que dela se tenha. A cultura não tem somente a ver com o presente do homem, muito menos com o seu passado, mas também com o seu futuro, porque é ela que the oferece a significação de que carece (FERNANDES, 2006, p. 261). Perante essa complexidade, e no sentido de oferecer respostas educativas mais eficientes por parte da escola, foram surgindo, por vezes, outros paradigmas pedagógicos enquadradores da função social da escola. Nesse sentido, podemos apontar o paradigma pedagógico da aprendizagem com pedagogos de referência como, por exemplo, Ferrière, Montessori e Dewey (TRINDADE; COSME, 2010). É o que se designa por movimento da Escola Nova. Nessa abordagem, o aluno é considerado o centro dos projetos da educação escolar. Ao contrário do paradigma da instrução para o qual os alunos eram uma espécie de tábua rasa, e o saber era considerado como um produto que se adquire, no paradigma da aprendizagem, esses mesmos alunos são detentores de teorias as quais poderão ser desenvolvidas e aperfeiçoadas à medida que vão sendo partilhadas e discutidas na sala de aula.

Também, e já numa perspetiva cultural, podemos apontar o paradigma pedagógico da comunicação o qual se interessa principalmente pela gestão da relação entre as singularidades dos sujeitos em formação e o património cultural em geral. Nessa abordagem, valorizam-se as interações que ocorrem na sala de aula como fator potenciador das aprendizagens dos alunos (TRINDADE; COSME, 2010).

A realidade educativa portuguesa é atualmente marcada pela encruzilhada desses paradigmas, que são, de certa forma, operacionalizados de acordo com as tendências de cada professor, estando na nossa opinião, longe de alcançar uma forma de atuação capaz de responder às necessidades atuais, entre elas a capacitação para a construção do conhecimento necessário à reflexividade perante as várias situações emergentes ao longo da vida.

Os processos de modernização trazem consigo a necessidade da reflexividade social (FERNANDES, 2006). Assim, nas sociedades complexas, os indivíduos "têm que se habituar a filtrar todo o tipo de informações relevantes para as diversas situações da sua vida e atuam habitualmente com base nesse processo de filtragem" (FERNANDES, 2006, p. 106). Numa situação de elevada reflexividade, exige-se maior seletividade de informação, maior grau de racionalidade e uma maior capacidade de processamento de dados. E, nessa linha de ideias, enquanto 
lugar público por excelência da educação, a escola terá de estar habilitada para (in) formar os cidadãos, desde logo as crianças sobre o processo de construção do conhecimento. Não basta ter acesso à informação e ao conhecimento produzido, há que saber construir informação e conhecimento. O aluno do presente deverá ser autónomo, saber pensar e construir a informação de que necessita. A escola tem um papel preponderante na função de ensinar a pensar e a construir saberes.

A escola deverá promover aprendizagens significativas e entender a diversidade e a complexidade do mundo como uma condição à partida. A escola terá de ser um espaço capaz de promover o desenvolvimento pessoal e social dos alunos, capacitando-os para viver num mundo tecnologicamente sofisticado, politicamente contraditório e, do ponto de vista das relações, bastante mais complexo. Como alerta Mário Sérgio Cortella (2014), não podemos continuar a viver numa escola em que os alunos pertencem efetivamente ao século XXI, mas os professores são do século XX e muitos deles utilizam métodos do século XIX.

Um tal compromisso pedagógico implica que os professores rompam com a conceção de uma Escola que se estruturou como um espaço onde se pretenderia ensinar tudo a todos como se todos fossem um só (BARROSO, 1995). É que a diversidade tornou-se uma presença efetiva nas nossas sociedades, desafiando-nos a reconhecer as singularidades de cada um e de cada caso como uma condição educativa. O quotidiano é diverso e complexo, é multicultural. De acordo com Boaventura Sousa Santos, o multiculturalismo é uma nova forma de globalização onde o mundo é um arco-íris de culturas (SANTOS, 1997). Este é um dos desafios que as sociedades pós-modernas lançam à escola: a aceitação e valorização das diferenças. E, a partir delas, promover a construção do conhecimento suscitando nos alunos um espírito crítico e reflexivo.

\subsection{A sala de aula como espelho da sociedade e a necessidade do professor reflexivo}

A escola constitui parte integrante de uma comunidade, com todas as dinâmicas envolventes sendo que a sala de aula não poderá ser senão o espelho da própria sociedade. Apesar dos currículos escolares e da normatividade que envolve a sala de aula, esta reflete, através dos elementos que a constituem, a sociedade, ou pelo menos uma parte dela, de acordo com o meio social, o económico e o cultural que a integram. Dessa forma, a sala de aula não pode deixar 
O manual escolar de Língua Portuguesa do 1 o Ciclo do Ensino Básico: inquietações em torno da desigualdade de género na escola

de ser afetada pelos problemas sociais das comunidades envolventes. Não há, portanto, uma porta que, ao se fechar, separe o mundo exterior da sala de aula. Aquele é visível, desde logo, nos comportamentos manifestados pelos alunos.

Perante os problemas escolares dos alunos, por vezes, resultantes dos problemas sociais (desemprego, desestruturação familiar, exclusão social e pobreza) vividos por estes, acontece o que Nóvoa (2005) designa por transbordamento de funções das escolas, originando novos questionamentos por parte da classe docente. A sala de aula não é, pois, um espaço isolado e artificial na sua totalidade. Se as matérias exigem ensino-aprendizagem, esse processo, por sua vez, exigirá a reflexividade necessária para a compreensão do aluno enquanto criança e da sua relação com o mundo exterior. Portanto a própria sala de aula suscita a reflexividade sobre o mundo e não poderá deixar de ser um espaço "[...] a reger por uma cultura da cidadania, na medida em que não existe verdadeira cidadania sem pensamento autónomo e crítico" (PERRENOUD, 2002, p. 129). A ideia de que o professor precisa de ser um investigador da própria prática não é recente. Encontramos originalmente em Dewey (1859-1952) essa preocupação. Não constitui nosso objetivo analisar os estudos sobre a prática docente, importa unicamente registar a ideia de que, face à complexidade social da sala de aula e às dinâmicas espontâneas que nela ocorrem, o professor deverá refletir, de forma metódica, sobre a sua atuação, assim como sobre a sua relação com os alunos.

Terá sido com Paulo Freire (1975), e a partir do seu conceito de educação problematizadora, que se começa a construir a necessidade de uma relação dialógica entre o educador e o educando, a qual potencia o espírito crítico e reflexivo dos seus intervenientes, conduzindo a uma ideia de escola entendida como comunidade de construção dialógica, abrindo o olhar para um outro paradigma escolar: o paradigma reflexivo.

A conceção de escola, defendida por Freire, está em consonância com o conceito de escola reflexiva (ALARCÃO; ROLDÃO, 2008; ALARCÃO; TAVARES, 2010), na assunção de uma escola inteligente, situada, com capacidade e flexibilidade de adaptação aos contextos complexos e de resposta incerta que caracterizam as situações escolares contemporâneas. A escola reflexiva constitui uma organização que continuamente se pensa a si própria, na sua missão social e na sua estrutura e se confronta continuamente com o questionamento da realidade e da intervenção num processo simultaneamente avaliativo e formativo (ALARCÃO; TAVARES, 2010). 
É uma escola que, por sua vez, se espelha através dos seus atores sociais, tendo como ponto de partida os contextos e as experiências reais da vida dos seus alunos. Nessa linha de pensamento, deveremos valorizar a reflexão e a análise de modo a permitir a compreensão dos contextos e dos problemas sociais que deles emergem (FREIRE, 1975). Os saberes não são vistos como algo que vem de fora, mas antes são produzidos na prática e na reflexão crítica sobre ela e sobre a prática dos outros.

Uma escola projeta-se e desenvolve-se a partir do conhecimento da sala de aula no sentido mais amplo, ou seja, a partir do conhecimento local, dos seus alunos, das famílias e dos demais atores locais. Implica o diagnóstico das necessidades locais, a caraterização das potencialidades, a consideração das caraterísticas na definição das suas metas e finalidades, assim como na definição das suas estratégias de ação. Nesse sentido, é urgente que "uma escola que se pensa a si própria, tenha um projeto específico contextualizado no seu ambiente histórico, geográfico e sociocultural e se responsabilize pelo seu cumprimento e pela avaliação da qualidade da sua conceção e realização" (ALARCÃO; TAVARES, 2010). Desse modo, a escola vai revelando a sua identidade enquanto organização e instituição formadora. Nesse contexto, o professor como interlocutor qualificado aproxima-se do conceito de professor problematizador (FREIRE, 1975), através do qual se visa afirmar a necessidade do professor refazer "[...] constantemente seu acto cognoscente, na cognoscibilidade dos educandos. Estes em lugar de serem recipientes dóceis de depósitos, são agora investigadores críticos, em diálogo com o educador, investigador crítico, também" (FREIRE, 1975, p. 99).

\section{A ESCOLA E O DISCURSO PEDAGÓGICO OFICIAL}

A escola é, pois, consensualmente aceite como um dos principais agentes de socialização do indivíduo e uma das instituições sociais fundamentais da sociedade e reflexo da sua própria evolução. O ato de educar constitui uma ação social com objetivos determinados e com grande alcance na formação dos povos. Como aponta Durkheim (2007, p. 53):

Em cada um de nós [...] existem dois seres que, apesar de apenas poderem ser separáveis por abstracção, não deixam de ser distintos. Um é feito de todos os estados mentais que apenas se ligam a nós mesmos e aos acontecimentos da nossa vida pessoal: é o que podemos chamar o ser individual. 
O manual escolar de Língua Portuguesa do 1 o Ciclo do Ensino Básico: inquietações em torno da desigualdade de género na escola

O outro é um sistema de ideias, de sentimentos e de hábitos que exprimem em nós, não a nossa personalidade mas o grupo ou os grupos diferentes de que fazemos parte: as crenças religiosas, as crenças e as práticas morais, as tradições nacionais ou profissionais, as opiniões coletivas de todo o género. O seu conjunto forma o social. Constituir este ser em cada um de nós, tal é o fim da educação.

A comunicação na sala de aula constitui um ponto de vista formalizado sobre a realidade social e através do ato de ensinar e aprender, é transmitida, interiorizada e pronta a ser (re) construída e (re) produzida (BERGER; LUKCMANN, 1997). A escola transmite saberes e valores, normas e costumes destinados ao aluno médio, com o intuito de formar de acordo com as exigências de um determinado tempo histórico e veiculando um ideologia dominante (BOURDIEU; PASSERON, 1970; BOURDIEU, 2010). A transferência do conhecimento é importante no tocante à produção e à reprodução das estruturas mentais da sociedade, as quais são também convenções sociais, construídas num determinado tempo histórico. A "ordem das coisas" (FOUCAULT, 2002) constitui o todo social integrado que a escola ajuda, de forma pedagógica e especializada, a transmitir às novas gerações, assumindo assim uma função de regulação da ordem social. A educação, e muito concretamente a escola, na figura do professor, prepara os indivíduos para o desempenho de papéis sociais previamente definidos. A mensagem transmitida pelo professor dá a conhecer saberes e conteúdos programáticos próprios dum discurso pedagógico oficial, e veicula ideias e ideologias dominantes (BOURDIEU; PASSERON, 1970). Para Bernstein (1996), o discurso pedagógico oficial é entendido como resultante de um conjunto de relações estabelecidas entre os vários campos implicados na sua geração, recontextualização e reprodução. Bernstein (1990) construiu um modelo, a partir da análise de mecanismos comunicacionais, que procura mostrar as múltiplas e complexas relações que intervêm na produção e reprodução daquele discurso. Assim, temos que: os princípios dominantes que são transmitidos pelo discurso regulador geral refletem posições de conflito e relações instáveis; existem sempre potenciais fontes de conflito, resistências e inércias entre os agentes políticos e administrativos do campo da recontextualização oficial, entre os diversos agentes do campo de recontextualização pedagógica entre o contexto primário do aluno/recetor da informação/mensagem e os princípios e as práticas da escola. Os professores e, nesse caso, os autores dos manuais escolares, 
poderão ou não reproduzir o código de transmissão educacional subjacente ao discurso pedagógico oficial. É esse dinamismo, entre as forças em presença, que, para Bernstein, possibilitará a mudança.

As dimensões mais importantes a considerar, nessa análise, relacionam-se com o contexto de recontextualização do discurso pedagógico. Assim, consideram-se os manuais escolares, concretamente, o Manual de Língua Portuguesa do 4응 ano de escolaridade (MLP), como um texto pedagógico recontextualizado. Desse modo, os manuais escolares veiculam um discurso pedagógico específico recontextualizado (BOTELHO; BORGES; MORAIS, 2002).

Por outro lado, sabendo, e de acordo com Giddens (2003), que as instituições sociais constituem o resultado de práticas sociais enraizadas no espaço e no tempo, as normas sociais, os valores influenciam a comunicação, designadamente a comunicação educacional, a educação possibilita a interiorização progressiva de papéis sociais de homem e de mulher, reproduz uma ideologia dominante, favorece a manutenção da ordem social e constitui um importante fator de regulação social através da produção e da transmissão do discurso pedagógico oficial.

No âmbito da criação e da recontextualização do discurso oficial pedagógico, encontram-se, em princípio, subjacentes as preocupações legislativas e normativas.

A questão social da desigualdade de género tem-se vindo a implementar, ainda que discretamente no cenário nacional, através da opinião pública e dos meios de comunicação social. Contudo, atendendo à legislação e às recomendações de natureza normativa emitidas, podemos afirmar que se trata de uma temática fortemente suportada por diretrizes dessa natureza. Assim, são vários os documentos que apelam a uma igualdade de género na escola, em Portugal. Para além das recomendações internacionais provenientes de organismos e instituições tais como As Nações Unidas, a União Europeia, o Conselho da Europa, existem diretrizes explícitas na Lei Portuguesa e em documentos afins que corroboram a atenção prestada a esta matéria. Na análise que se apresenta, focou-se a atenção na Constituição da República Portuguesa (ASSEMBLEIA DA REPÚBLICA, 2005), na Lei de Bases do Sistema Educativo (ASSEMBLEIA DA REPÚBLICA, 1986) e nas orientações patentes no guia da Comissão para a Cidadania e Igualdade de Género (2009).

Poder-se-á ler na CRP no seu artigo 13o o Princípio da Igualdade no qual se afirma: 
O manual escolar de Língua Portuguesa do 1 o Ciclo do Ensino Básico: inquietações em torno da desigualdade de género na escola

\section{Artigo 13.ㅇ}

\section{(Princípio da igualdade)}

1. Todos os cidadãos têm a mesma dignidade social e são iguais perante a lei.

2. Ninguém pode ser privilegiado, beneficiado, prejudicado, privado de qualquer direito ou isento de qualquer dever em razão de ascendência, sexo, raça, língua, território de origem, religião, convicções políticas ou ideológicas, instrução, situação económica, condição social ou orientação sexual.

Tendo como objeto de análise o MLP, convém destacar igualmente que a Lei de Bases do Sistema Educativo (ASSEMBLEIA DA REPÚBLICA, 1986) refere, no ponto 2. do seu arto. 1으, que o sistema educativo deve promover "uma acção formativa em ordem ao desenvolvimento global da personalidade, o progresso social e a democratização da sociedade" e na alínea i) do seu 3o arto. "assegurar a igualdade de oportunidades para ambos os sexos".

Esses direitos fundamentais constituem marcos basilares da fundação da democracia portuguesa, procurando garantir a universalidade e a igualdade das condições sociais de existência e tornaram-se um estandarte do aprofundamento e do desenvolvimento da cidadania. Nessa linha de preocupações, surge, por volta dos anos 70 em Portugal, a Comissão para a Igualdade de Género, atualmente designada Comissão para a Cidadania e Igualdade de Género. Assim, em 2009, essa Comissão (2009) lança um guia prático de orientações a considerar na produção de manuais escolares. Esse guia apresenta, entre outros, o seguinte objetivo: "apoiar as Editoras e respetiv@s colaborador@s na concepção e produção de manuais escolares e de produtos educativos multimédia que sejam de forma inequívoca, promotores da igualdade entre os sexos" (PAIS apud NUNES, 2009). Esse guia sistematiza um conjunto de princípios e de práticas a ter em conta na elaboração dos manuais escolares, salientando que: "Promover a igualdade entre mulheres e homens: exige o equilíbrio na sua visibilidade e pressupõe que as referências ao feminino e ao masculino sejam igualmente significativas, contextualizadas, explicitadas e valorizadas" (NUNES, 2009, p. 16).

É com base nos fatores referidos e tendo como ponto de partida o MLP do 40 ano de escolaridade, como produto e resultado de um discurso pedagógico recontextualizado e oficial, e as orientações normativas e legislativas referenciadas na Constituição da República Portuguesa, na Lei de Bases do Sistema Educativo e 
nas orientações da Comissão para a Cidadania e Igualdade de Género que partimos para uma travessia pelo manual de língua portuguesa com um olhar informado sobre a questão da diferenciação social entre homem e mulher veiculada pelo livro em questão.

\section{A DESIGUALDADE DE GÉNERO: INFORMAR O OLHAR}

A noção de género prende-se com a diferenciação social entre homem e mulher, ultrapassando as diferenças físicas, biológicas e culturais. Homens e muIheres são diferentes. A questão que se coloca é quando as diferenças resultam duma desigualdade e ou hierarquização dos papéis e estatutos sociais associados ao homem e à mulher. O feminino e o masculino constituem mundos de sentido e de significados demasiadamente vastos para uma análise meramente sociológica. É sem dúvida um conceito multidimensional.

Nascido no intenso debate que o feminismo da segunda vaga gerou, o conceito de género difundiu-se rapidamente nas ciências sociais, se considerarmos a cronologia de alguns textos de referência, como o de Ann Oakley (1972) para a sociologia, o de Rhoda Unger (1979) para a psicologia social e o de Joan Scott (1988) para a história. (AMÂNCIO, 2003, p. 687).

As diferenças são, pois, do ponto de vista da análise, vistas de várias formas no âmbito das ciências sociais. No entanto todas elas assentam numa condição: o resgate do conceito junto da biologia e da medicina. A noção de diferenciação social ultrapassa as condições físicas e biológicas do conceito e entra no universo das relações de poder e no campo do simbólico, através de comportamentos e da construção social de ideias preconcebidas e estereótipos sobre homens e muIheres, resultando numa forma de desigualdade social, à qual se juntam, desde logo, as questões do trabalho e da condição feminina.

O conceito de género surge intimamente ligado às diferenças entre homens e mulheres numa perspetiva de desigualdade social que parte de lugares sociais inferiores e superiores ocupados respetivamente por mulheres e homens e favorece a construção social de crenças, saberes e valores sobre os sexos, reproduzindo e legitimando a própria desigualdade. Refere-se a uma questão de relação entre forças sociais, assinalada pela assimetria no plano dos significados e define um contexto de dominação (AMÂNCIO, 2003). Por outro lado, e mesmo analisando um plano partilhado de vida, homem e mulher, portanto, um casal, Bernard (1982) 
regista que o casamento é vivido de modos diferentes, entre homem e mulher, os homens, regra geral, pensam ter mais poder do que efetivamente têm, e as mulheres, por sua vez, julgam ter menos poder do que na verdade têm.

Do ponto de vista sociológico, a questão do olhar sobre a noção de género coloca-se fundamentalmente em três frentes de análise: a hierarquização de posições ocupadas na sociedade por homens e por mulheres, posições diferentes, e, sobretudo, desiguais; a desigualdade social entre homens e mulheres que resulta da própria organização da sociedade de acordo com papéis sociais no feminino e papéis sociais no masculino. Parte-se do princípio, porque a história o corrobora, de que as mulheres normalmente apresentam menos recursos materiais do que os homens, um estatuto social inferior e ocupam posições com menos poder do que os homens. Nessa perspetiva, o género é considerado um elemento que condiciona a posição social dos indivíduos, à semelhança do que acontece com os fatores do tipo classe social, rendimentos económicos, profissão e nível de escolaridade. Por último, aponta-se uma terceira frente de análise, a da socialização dos indivíduos com base nas expetativas sociais criadas em função do género, facilitando a reprodução de mecanismos de natureza diferenciadora e discriminatória na relação entre homens e mulheres. Essas três frentes de análise encontram-se interrelacionadas, e intimamente ligadas, integrando as próprias maneiras de ser e de estar no feminino e no masculino.

Acresce referir que o conceito de género surge no âmbito de um contexto social e político de alargamento e aprofundamento dos direitos nas sociedades contemporâneas, ao qual não são alheios os documentos internacionais e oficiais tais como a Carta das Nações Unidas (1945), a Declaração Universal dos Direitos do Homem (1948) e, posteriormente, a Convenção sobre a Eliminação de Todas as Formas de Discriminação contra as Mulheres (1979). Com efeito, o século $\mathrm{XX}$ tem, entre outros, dois importantes protagonistas: as mulheres e o amor. As primeiras foram ultrapassando as limitações impostas e mostraram, a partir de diversos contextos sociais, o que sabiam, o que faziam e o que estavam dispostas a dar, muito para além da função materna que as tinham querido limitar. De uma ideia de mulher-natureza, circunscrita no ser e na acção aos condicionamentos biológicos, passámos para uma ideia de mulher-indivíduo, dona do seu destino, responsável por si e pelos seus actos. Processo de transformação ainda em curso, com atalhos e curvas sinuosas (TORRES, 2002, p. 573). 
As lutas simbólicas do poder, as quais ocorrem num contexto de desigualdades sociais, são as menos visíveis do ponto de vista social e as mais morosas no tempo, fazendo-se delas mecanismos próprios do devir das sociedades.

\section{ANÁLISE DO MANUAL ESCOLAR DE LÍNGUA PORTUGUESA DO 4 ANO DO 1 CICLO}

\subsection{Metodologia de análise: a proposta de Eugénio Brandão}

A análise sociológica dos manuais escolares constitui uma área de grande interesse académico. As principais dimensões desenvolvidas têm-se centrado quer no levantamento de estereótipos de género e culturais (FONTAINE, 1977; BRANDÃO, 1979; ABRAHAM, 1989), quer no estudo da importância e do papel das relações socioeconómicas que influenciam a publicação e a seleção dos manuais (APPLE; CHRISTIAN-SMITH, 1991). Contudo, embora exista produção académica e científica de referência, a análise sociológica, nesse âmbito, apresenta dados e explicações ainda insuficientes face à complexidade da temática.

A grande questão que se coloca é: O MLP do 4o ano é discriminatório? Esta análise procura sinalizar e registar, em quantidade, as "imagens" do feminino e do masculino veiculadas pelos textos, sugerindo ideias de confirmação de traços de desigualdade de género e de estereotipia, o número de autores femininos e masculinos atravessando alguns indicadores tais como: figuras centrais patentes nos textos, figuras históricas, profissões transmitidas no masculino e no feminino, imagens valorativas de caraterísticas de género e certas atitudes formativas com base na desigualdade de género.

Parte-se do pressuposto de que, se houver uma exposição constante de textos discriminatórios, as crianças tendencialmente poderão adquirir determinadas ideias preconcebidas, construindo elas próprias "territórios simbólicos" sobre a colocação social dos sexos, que lhes condicione as respetivas possibilidades de formação e de realização profissional e pessoal. Nesse sentido, pretende-se alertar para a existência de ideias acerca dos sexos as quais se transmitem de geração em geração no contexto escolar e se vão enraizando na sociedade.

Propõe-se uma análise de conteúdo dos textos mencionados e patentes no Manual de Língua Portuguesa do 4ㅇa ano de escolaridade, através de um processo de categorização com base nas imagens e representações de género, veiculadas 
pelos textos em questão. A metodologia operacionaliza-se recorrendo a uma grelha analítica e de categorização com base nos seguintes elementos: identificação e breve contextualização do texto, tipo de texto, categorias de imagens veiculadas sobre o feminino e o masculino, com algumas significações associadas, tendo em conta o número de ocorrências. As categorias de análise consideradas inspiram-se na proposta apresentada e desenvolvida por Eugénio Brandão (1979) e prendem-se com os seguintes elementos: autores dos textos - masculino/feminino; as figuras apresentadas nos textos - figuras familiares, figuras históricas, figuras profissionais e figuras centrais e ou de referência, atividades associadas ao género; atividades profissionais associadas ao género, atitudes formativas associadas, também elas à questão do género.

A análise reporta portanto aos textos em questão assim como às ilustrações que os acompanham no sentido de que, através da veiculação das imagens/territórios simbólicos de significado, estamos perante situações de desigualdade de género.

A apresentação de dados procura demonstrar o (des)equilíbrio existente entre as imagens do masculino e as imagens do feminino veiculadas pelo referido manual e verificar a ocorrência da desigualdade de género e a existência de estereótipos baseados na desigualdade de género.

Na apresentação dos resultados, houve a preocupação em manter anónimos quer o/as autore/as do manual assim como os autores, em geral, dos textos analisados.

Os resultados que se apresentam devem ser ressalvados relativamente aos critérios de representatividade e de generalização pois reportam apenas a um Manual de Língua Portuguesa e trata-se dum estudo (de) limitado.

\subsection{Registando a desigualdade de género}

O folhear dos livros é um hábito que se vai adquirindo desde a infância. Independentemente dos ambientes familiares serem ou não povoados de livros, o certo é que o manual de língua portuguesa constitui para muitas crianças o primeiro livro de leitura sistemática. As figuras e as imagens que acompanham o manual são extremamente importantes e sugerem outras formas de leitura sobre o mundo. São especialmente importantes quando são visionadas com regularidade levando à memorização pelo constante reler e reviver das histórias. 


\subsubsection{As imagens/figuras e ilustrações contidas no Manual de Língua Portuguesa por número de ocorrências}

\begin{tabular}{|l|c|}
\hline Ilustrações & Total de ocorrências \\
\hline Masculinas & 24 \\
\hline Femininas & 12 \\
\hline Neutras & \\
Animais masculinos & 7 \\
Animais femininos & \\
Animais em conjunto & 4 \\
Objetos & 1 \\
Plantas & 5 \\
Cenário & 5 \\
\hline
\end{tabular}

As figuras ilustradas que acompanham os textos do manual são predominantemente masculinas. Constituem imagens diretas de homens ou rapazes e ou sugerem o sexo masculino, por exemplo, mediante a construção de um cenário composto por elementos masculinos, tais como cavalos e aviões com animais masculinos.

O mundo das ilustrações do manual é assim fundamentalmente masculino. A relação de imagens é de 24 imagens masculinas para 12 imagens femininas.

Numa análise mais fina, podemos encontrar, através das próprias imagens, algumas representações que, de certa forma, reforçam a ideia central de diferença própria de género. Observa-se, por exemplo, a representação do homem mediante a veiculação das seguintes imagens sugestionáveis:

- A manipular uma marioneta de letras

- A caçar vampiros, sugerindo coragem e valentia

- A viajar, sugerindo aventura

- Homem sábio na figura do avô como contador de histórias aos netos e como escritor

- Homem distribuidor de presentes: a figura do Pai Natal

- Homem como figura histórica representando D. Afonso Henriques o conquistador

- Homem como navegador à descoberta do mundo 
- Rapazes a exercerem o direito de voto supervisionados por uma figura masculina

- Rapazes a jogarem futebol

- Rapaz observador da natureza

- Homem como imperador, sugerindo poder e riqueza

- Na versão BD, as figuras masculinas estão colocadas ao centro, ganhando uma forma destacada no centro da perspetiva do olhar

- O homem como pai que faz magia e enriquece a infância dos filhos

- O homem como símbolo da sabedoria, poder e proteção, associado à figura histórica do Faraó e simbólica da esfinge egípcia

Por seu lado, a figura feminina surge apresentando as seguintes imagens também elas sugestionáveis :

- uma mulher à janela

- raparigas com ar assustado

- como criada do imperador

- como mãe com bebé ao colo

- ao colo da mãe

- como princesa

- ligada aos afetos

- a olhar para uma flor murcha no chão

- a cheirar uma flor

- rapariga à porta do castelo debaixo de chuva

- como guia turística

Poder-se-á afirmar que, perante o exposto, as ilustrações do manual desfavorecem a mulher, desde logo, em quantidade. Por cada ilustração feminina ocorrem 2 masculinas.

Em termos de análise qualitativa, as ilustrações tendem a representar o homem como um ser ativo, corajoso, valente e sábio, e a mulher como menos ativa e mais contemplativa (à janela, a olhar para as flores...), associando-se a ela fatores como o medo, os afetos e o ato de cuidar. 


\subsubsection{Os textos que compõem o MLP do $4 \stackrel{0}{\circ}$ ano}

Os textos analisados são de diversos tipos: prosa, poema e peças teatrais. A leitura dos textos, em prosa e em poema, possibilita uma veiculação de informação considerada de interesse fundamental na aprendizagem da criança. Se consideramos que a criança lê e relê os textos, até para realizar os exercícios solicitados, facilmente imaginamos uma repetição de informação que poderá ter tendência a cristalizar maneiras de ver e pensar o mundo das próprias crianças. O mesmo acontece com as peças teatrais, estas são decoradas, interiorizadas e encenadas, o que poderá produzir efeitos significativos no âmbito do processo de socialização no que concerne ao entendimento do mundo.

\subsubsection{Os/as autore/as dos textos do MLP}

\begin{tabular}{|l|c|}
\hline Autores & Totais \\
\hline Masculinos & 34 \\
\hline Femininos & 18 (2 são de autoras em conjunto) \\
\hline Mistos & 1 \\
\hline Sem autor & 6 \\
\hline Sites & 2 \\
\hline
\end{tabular}

Os textos apresentados no manual são, em grande maioria, escritos por homens. Deve-se ressalvar que, atendendo ao processo de socialização, as maneiras de ver o mundo poderão ser diferentes entre homem e mulher e não levar a um esbatimento da desigualdade de género no tocante a este assunto.

Também por outro lado, o facto de termos em presença no manual um número significativamente maior de homens escritores poderá conduzir a um entendimento de que o mundo das letras é predominantemente masculino.

\subsubsection{As figuras familiares veiculadas pelos textos do MLP}

\begin{tabular}{|l|c|}
\hline Figuras familiares que ocorrem nos textos & № de ocorrências \\
\hline Mãe & 3 \\
\hline Pai & 2 \\
\hline Avô & 1 \\
\hline Irmão & 1 \\
\hline Tio & 1 \\
\hline
\end{tabular}


A mãe é a figura familiar que mais ocorre. Não tem profissão e dedica-se ao ato de cuidar e educar sugerindo, relativamente a uma eventual profissão/ocupação no futuro, a ocupação de dona de casa. A figura paterna surge associada às brincadeiras na infância e à educação no que concerne à superação de obstáculos. O avô surge como contador de histórias e feitos relacionados com a valentia e a bravura. Por fim, as figuras de irmão e tio assumem um papel periférico, mas no sentido do amparo.

\subsubsection{As figuras históricas apresentadas e veiculadas no MLP}

\begin{tabular}{|l|l|}
\hline Figuras históricas & Tipo de referência \\
\hline D. Afonso Henriques & $\begin{array}{l}\text { Referência direta e biográfica } \\
\text { 1o rei de Portugal }\end{array}$ \\
\hline Tristão Vaz Teixeira & $\begin{array}{l}\text { Referência direta } \\
\text { Navegador português }\end{array}$ \\
\hline João Gonçalves Zarco & $\begin{array}{l}\text { Referência direta } \\
\text { Navegador português }\end{array}$ \\
\hline Vasco da Gama & $\begin{array}{l}\text { Referência indireta através do nome do neto } \\
\text { Navegador português }\end{array}$ \\
\hline Pedro Álvares Cabral & $\begin{array}{l}\text { Referência indireta através do nome do neto } \\
\text { Navegador português }\end{array}$ \\
\hline Bartolomeu Dias & $\begin{array}{l}\text { Referência indireta através do nome do neto } \\
\text { Navegador português }\end{array}$ \\
\hline Rainha D. Amélia & $\begin{array}{l}\text { Referência direta como mulher de D. Carlos I e que teve } \\
\text { iniciativa de fundar o museu Nacional dos Coches }\end{array}$ \\
\hline
\end{tabular}

As figuras históricas que ocorrem são, na sua totalidade, pertencentes ao sexo masculino e associam-se aos grandes feitos da História de Portugal. Apenas surge uma referência a uma figura histórica feminina e ligada ao marido. Verifica-se que a figura histórica é valorizada no manual, mas quase exclusivamente associada ao mundo masculino, a determinados traços psicológicos e comportamentais nos quais as dimensões da valentia, coragem e aventura estão regularmente presentes. A figura histórica feminina é claramente subvalorizada. A história de Portugal transmitida no MLP realiza-se totalmente no domínio do masculino. 
4.2.6 Presença de figuras centrais por tipo de texto

\begin{tabular}{|c|c|c|c|c|c|c|}
\hline \multirow{2}{*}{ Tipo de texto } & \multirow{2}{*}{$\begin{array}{l}\text { № de } \\
\text { textos }\end{array}$} & \multicolumn{2}{|c|}{ Presença } & \multicolumn{2}{|r|}{ Presença } & \multirow{2}{*}{$\begin{array}{c}\text { Total de } \\
\text { ocorrências }\end{array}$} \\
\hline & & Masculina & Feminina & Coletiva & Indiferenciada ${ }^{2}$ & \\
\hline Prosa & 26 & 16 & 5 & 3 & 2 & 26 \\
\hline Poema & 20 & 4 & 1 & & 15 & 20 \\
\hline Peça teatral & 2 & 2 & & & & 2 \\
\hline Texto informativo & 6 & 2 & 2 & & 2 & 6 \\
\hline Texto publicitário & 1 & & & & 1 & 1 \\
\hline Banda desenhada & 2 & 2 & & & & 2 \\
\hline
\end{tabular}

O MLP contém textos diversos de acordo com a tipologia conforme o descrito no quadro anterior. A maior parte dos textos corresponde ao texto em prosa. Assim na totalidade dos 55 textos patentes no manual, 26 são do tipo prosa, logo seguidos dos poemas (20 textos). Existem seis textos de natureza informativa, dois do género dramático e um texto publicitário. No que concerne aos textos em prosa, podemos afirmar que, nos 26 textos, são veiculadas 16 figuras centrais masculinas, que vão desde as figuras históricas, às figuras familiares como avô, pai e filho, figuras profissionais no masculino, como adiante demonstraremos, os protagonistas das histórias são masculinos, e ocorrem apenas cinco figuras femininas, secundárias, como mãe, uma profissão ligada à área da educação e ou uma princesa. Por sua vez, os textos relativos à tipologia poema, apresentam uma maior ocorrência de figuras de natureza indiferenciada, na medida em que uma parte significativa dos poemas é relativa aos elementos pertencentes ao universo da natureza, designadamente animais e plantas. Os textos informativos apresentam uma distribuição das figuras por categorias mais equilibrada. Resta referir o texto de natureza publicitária, o qual reporta à projeção da Ilha das Flores no mercado turístico.

As figuras centrais patentes no manual são na sua esmagadora maioria masculinas.

No manual em análise, o mundo surge aos olhos da criança predominantemente masculino não só pela veiculação das imagens transmitidas como também

\footnotetext{
${ }^{2}$ Entende-se por indiferenciada o facto de o coletivo e ou cenário ser constituído ou animais e ou plantas assim como outras referências da natureza.
} 
pelos papéis sociais e valorações a eles associados que são diariamente transferidos para as crianças quer diretamente, através da leitura realizada pelas próprias, quer indiretamente pela leitura efetuada pelo/a professor/a.

O protagonismo é sistematicamente assumido pela figura masculina, o que poderá levar a uma discriminação de género através das presenças contabilizadas assim como a consequências no próprio processo de socialização, restringindo à figura masculina, e aos respetivos valores associados, a diversidade de estruturas sociais de oportunidades e do próprio mundo da socialização. Por seu turno, a figura feminina é veiculada em muito menor número de vezes e acaba por sugerir um condicionamento no leque de escolhas de socialização junto dos mundo da infância.

\subsubsection{Profissões transmitidas no masculino e no feminino no MLP}

Lançando um olhar mais fino poderemos constatar o processo de veiculação de algumas profissões no manual em análise. Assim, poderemos dispor a informação da seguinte forma:

\begin{tabular}{|l|l|}
\hline Profissões transmitidas no Masculino & Profissões transmitidas no Feminino \\
\hline Médico & Educadora Social \\
Engenheiro & Guia turística \\
Professor & \\
Polícia & \\
Advogado & \\
Veterinário & \\
Juiz & \\
Programador informático & \\
\hline
\end{tabular}

Na mesma linha de análise, constatamos que as profissões são, na sua globalidade, transmitidas numa dimensão fortemente masculina. São os homens que assumem ou ambicionam os papéis profissionais de médico, juiz, polícia, professor, engenheiro, por exemplo, fazendo coincidir as suas escolhas com um conjunto de profissões tradicionalmente consideradas prestigiantes do ponto de vista social e curiosamente uma profissão ligada à tecnologia. No MLP do 4 으 ano de escolaridade, assistimos apenas à veiculação de duas profissões no feminino: educadora social e guia turística. A primeira respeita a uma profissão na área da 
educação, o que corresponde à veiculação de padrões dominantes na escolha da profissão. De facto, a sociedade portuguesa apresenta números expressivos no que concerne às mulheres que desempenham profissões na área da educação. Também, e de acordo com os dados estatísticos relativos à distribuição de alunos do sexo feminino em \% dos matriculados no ensino superior por área de educação e formação, verifica-se que, desde 1991, se assiste a um padrão percentual que ronda os $80 \%$ de mulheres inscritas na área da Educação, relativamente ao seu percurso formativo e académico (www.pordata.pt). A segunda profissão veiculada no feminino é a profissão de guia turística apelando, contudo, a características que, de certo modo, estereotipam a figura da guia turística: "alta, magra, elegante e simpática".

Por parte da criança, a escolha da profissão prende-se com as expetativas relativamente ao futuro, criadas em função do meio social a que pertence, e com a veiculação de imagens/exemplos com os quais contata diariamente. Tal é o caso da socialização em meio escolar. Nesse sentido, podemos apontar o papel crucial dos manuais escolares na veiculação da oferta dum leque diversificado ou não de profissões para ambos os sexos. Perante os dados expostos, concluímos que são apresentadas significativamente mais possibilidades profissionais masculinas do que femininas, ficando o mundo do trabalho no feminino muito circunscrito e reduzido a duas profissões. Além dessa conclusão, poderemos ainda evocar que, no referido manual, as profissões socialmente mais importantes e mais bem remuneradas estão reservadas ao homem.

\section{NOTAS CONCLUSIVAS: ENSAIO PARA A CONSTRUÇÃO DE TERRITÓRIOS SIMBÓLICOS MARCADOS PELA DESIGUALDADE DE GÉNERO E PARA A NECESSIDADE DO PROFESSOR REFLEXIVO}

No MLP do 4ㅇ ano de escolaridade, verificamos que o mundo, as suas visões, os seus valores e as suas normas são transmitidos no masculino. São muito poucas as referências ao universo feminino.

As referências ao masculino são diversas e socialmente favoráveis ao contrário do que acontece com as referências ao universo feminino. Estas, além de escassas, são muito pouco diversificadas.

Nesse sentido, concluímos que as imagens veiculadas, em geral, pelo MLP do 4 ㅇano de escolaridade, possibilitam a construção de territórios simbólicos dos 
universos do feminino e do masculino e de forma desigualitária. Podemos ainda acrescentar que os territórios simbólicos são construídos em função apenas do número de imagens veiculadas, procurando apresentar uma análise isenta ao nível das observações de natureza analítica.

Assim, ao homem são associadas situações e processos socialmente favoráveis possibilitando a construção de imagens favorecidas e positivas em torno dos seguintes territórios simbólicos: sucesso, trabalho, prestígio, conhecimento, aventura, coragem, persistência.

Por sua vez, à mulher são associadas situações e processos socialmente desfavoráveis, possibilitando, por conseguinte, a construção de imagens desfavorecidas em torno dos seguintes territórios: vulnerabilidade, fragilidade, sensibilidade, necessidade de proteção, tristeza.

Em jeito de conclusão, e numa postura de cidadania, pensamos apontar, com legitimidade, as seguintes preocupações a ter em linha de conta em trabalhos posteriores: quais são os valores e os saberes veiculados? Quem os determina e porquê estes? Quem assume essa responsabilidade? Até que ponto o professor é efetivamente reflexivo face a essa temática?

Volvidos cerca de 40 anos após a Revolução do 25 de abril, que coloca Portugal no mundo da democracia, estamos perante um cenário, oficialmente instituído, marcado pela desigualdade de género, o que nos leva a alertar para a necessidade do professor reflexivo.

O professor não é o único agente educativo, mas será seguramente o interlocutor privilegiado junto das crianças e deverá estar vigilante face a esta realidade.

\section{REFERÊNCIAS}

ABRAHAM, J. Teacher ideology and sex roles in curriculum texts. British Journal of Sociology of Education, v. 10, n. 1, p. 33-51, 1989.

ALARCÃO, I.; ROLDÃO, M. C. Supervisão: um contexto de desenvolvimento profissional dos professores. Mangualde, Portugal: Pedago, 2008.

ALARCÃO, I.; TAVARES, J. Supervisão da prática pedagógica. Uma perspectiva de desenvolvimento e aprendizagem. 2. ed. Coimbra, Portugal: Almedina, 2010.

AMÂNCIO, Lígia. O género no discurso das ciências sociais. Análise Social, v. 38, n. 168, p. 687-714, 2003. Disponível em: <http://analisesocial.ics.ul.pt/ documentos/1218791078B9rDE5id4Po89MU8.pdf>. 
APPLE, M. W.; CHRISTIAN-SMITH, L. K. (Ed.). The politics of the textbook. Londres: Routledge, 1991.

ASSEMBLEIA DA REPÚBLICA. Constituição da República Portuguesa. 7. rev. constitucional. Lisboa, 2005. Disponível em: <http://www.parlamento.pt/Legislacao/Paginas/ ConstituicaoRepublicaPortuguesa.aspx>.

. Lei de Bases do Sistema Educativo n. 46/86, de 14 de outubro. Lisboa, 1986.

BARROSO, João. Para o desenvolvimento de uma cultura de participação na escola. Lisboa: Instituto de Inovação Educacional, 1995.

BERGER, P.; LUCKMANN, T. A construção social da realidade. Petrópolis, RJ: Vozes, 1997. BERNARD, Jessie. The future of marriage. Yale: University Press, 1982.

BERNSTEIN, B. Pedagogy, symbolic control and identity. Theory, research, critique. 1. ed. Londres: Taylor and Francis, 1996.

. Poder, education y conciencia. Sociologia de la transmission cultural. 1. ed. Barcelona : El Roure, 1990.

. On pedagogic discourse. In: RICHARDSON, J. G. (Ed.). Handbook of theory and research for sociology of education. Nova lorque: Greenwood Press, 1986.

BOTELHO, A.; BORGES, C.; MORAIS, A. As imagens dos manuais escolares de ciências. Análise dos princípios de igualdade entre homens e mulheres. 2002. Disponível em: <http://essa.ie.ulisboa.pt/ficheiros/artigos/revistas_com_revisao_cientifica/2002_ asimagensdosmanuaisescolares.pdf>.

BOURDIEU, P. A distinção: uma crítica social da faculdade do juízo. Lisboa: Edições 70, 2010.

- A escola conservadora: As desigualdades frente à escola e à cultura. Tradução de A. J. Gouveia. In: NOGUEIRA, M. A.; CATANI, A. (Org.). Escritos e educação. Petrópolis, RJ: Vozes, 2002. p. 39-64.

BOURDIEU, P.; PASSERON, J.-C. A reprodução: elementos para uma teoria do sistema de ensino. Lisboa: Editorial Veja, 1970.

BRANDÃO, Eugénio. Estereótipos em manuais escolares. Lisboa: Comissão da Condição Feminina, 1979. Cadernos da Condição Feminina, 9.

CANÁRIO, Rui. Educação de adultos: um campo e uma problemática. Lisboa: Educa, 1999. CORTELLA, Mário S. Educação, escola e docência: novos tempos, novas atitudes. São Paulo: Cortez, 2014.

DURKHEIM, E. Educação e Sociologia. Coimbra: Biblioteca 70, 2007. 
O manual escolar de Língua Portuguesa do 1 o Ciclo do Ensino Básico: inquietações em torno da desigualdade de género na escola

FERNANDES, A. T. Monotonia democrática e diluição das regulações sociais. Porto, Portugal: Afontamento, 2006.

FONTAINE, Anne-Marie. A discriminação sexual dos papéis sociais nos manuais portugueses de aprendizagem da leitura. Revista Portuguesa de Pedagogia, Coimbra, Portugal, ano XI, separata, 1977.

FOUCAULT, M. The order of things: an archeology of the human sciences. New York: Routledge, 2002.

FREIRE, Paulo. Pedagogia do oprimido. Porto, Portugal: Afrontamento, 1975.

GIDDENS, A. A constituição da sociedade. São Paulo: Martins Fontes, 2003.

NÓVOA, António. Evidentemente, histórias da educação. Edições Asa, 2005. Disponível em: <https://pt.scribd.com/document/311520466/ Antonio-Novoa-Evidentemente-Historias-da-Educacao-2005-pdf>.

NUNES, M. Teresa. Presidência do Conselho de Ministros . O feminino e o masculino nos materiais pedagógicos (in)visibilidades e (des)equilibrios. Lisboa: COMISSÃO PARA A CIDADANIA E IGULDADE DE GÉNERO, 2009.

PERRENOUD, P. A prática reflexiva no ofício do professor: profissionalização e razão pedagógica. Porto Alegre: Artmed, 2002.

. La Construcción del êxito e del fracasso escolar: Madrid: Ediones Morata, 1990.

SANTOS, Boaventura Sousa. Para uma concepção multicultural dos direitos humanos. Revista Crítica de Ciências Sociais, Coimbra, Portugal, n. 48, p. 11-32, jan. 1997.

SARMENTO, M. J. Lógicas de aç̧ão nas escolas. Lisboa: Instituto de Inovação Educacional, 2000a.

SARMENTO, M. J. Os ofícios da criança. In: CONGRESSO INTERNACIONAL - OS MUNDOS SOCIAIS E CULTURAIS DA INFÂNCIA. Actas... Braga: IEC/Uminho, 2000b. vol. II.

TORRES, Anália. Casamento: conversa a duas vozes eme três andamentos. Análise social, Lisboa, v. 37, n. 163, p. 569-602, 2002. Disponível em: <http://analisesocial.ics.ul.pt/do cumentos/1218733072F9uQX5hx1Ry60HQ5.pdf>.

TRINDADE, R.; COSME, A escola, educação e aprendizagem: desafios e respostas pedagógicas. Rio de Janeiro: WAK, 2010. 


\section{Sobre a autora:}

Florbela Samagaio: É licenciada em Sociologia desde 1992 pela Faculdade de Letras da Universidade do Porto, onde concluiu o Mestrado em 1997, no curso de Sociologia - Poder Local, Desenvolvimento e Mudança Social, e o Doutoramento em Sociologia em 2014. Iniciou a sua atividade profissional em projetos de intervenção social e desenvolvimento local, tendo realizado a Formação JADE II (Jovem Agente de Desenvolvimento). É docente na Escola Superior de Educação de Paula Frassinetti desde 1997. É investigadora integrada do Instituto de Sociologia da Universidade do Porto. Tem desenvolvido trabalhos nas áreas da Sociologia da Pobreza e da Exclusão Social, das Políticas Sociais, da Educação e das Metodologias de Investigação. E-mail: florbelamsamagaio@gmail.com

\section{Recebido em dezembro de 2017}

Aprovado em fevereiro de 2018 